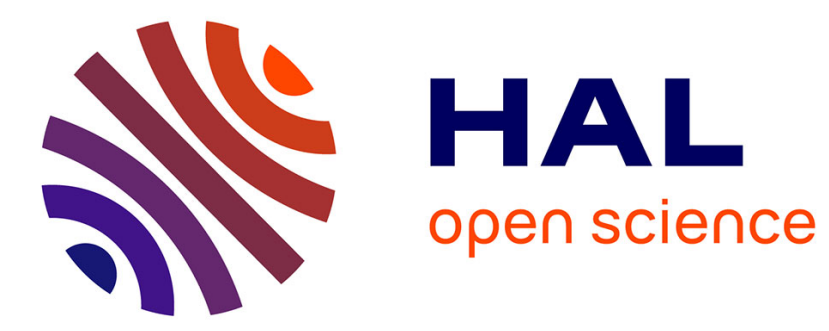

\title{
Improvement of 3D mean field models for capillarity-driven grain growth based on full field simulations
}

Ludovic Maire, Benjamin Scholtes, Charbel Moussa, Nathalie Bozzolo, Daniel Pino Muñoz, Marc Bernacki

\section{To cite this version:}

Ludovic Maire, Benjamin Scholtes, Charbel Moussa, Nathalie Bozzolo, Daniel Pino Muñoz, et al.. Improvement of 3D mean field models for capillarity-driven grain growth based on full field simulations. Journal of Materials Science, 2016, 51 (24), pp.10970-10981. 10.1007/s10853-016-0309-6 . hal-01369919

HAL Id: hal-01369919

https://hal-mines-paristech.archives-ouvertes.fr/hal-01369919

Submitted on 16 May 2018

HAL is a multi-disciplinary open access archive for the deposit and dissemination of scientific research documents, whether they are published or not. The documents may come from teaching and research institutions in France or abroad, or from public or private research centers.
L'archive ouverte pluridisciplinaire HAL, est destinée au dépôt et à la diffusion de documents scientifiques de niveau recherche, publiés ou non, émanant des établissements d'enseignement et de recherche français ou étrangers, des laboratoires publics ou privés. 


\title{
Improvement of 3-D mean field models for capillarity driven grain growth based on full field simulations
}

\author{
L.MAIRE $\cdot$ B.SChOlteS $\cdot$ C.MOUSSA . \\ N.Bozzolo · D.Pino MUÑoz · M.BERnACKI
}

Received: date / Accepted: date

\begin{abstract}
In the present study, mean field models of grain growth (Hillert and Burke-Turnbull models) are compared with 3-D full field simulations considering an isotropic grain boundary energy and mobility and under the absence of second-phase particles. The present 3-D full field simulations are based on a level set description of the grain interfaces within a finite element framework. The digital initial microstructures are generated using a coupled "Vorono"1-Laguerre/dense sphere packing" algorithm. Based on full field simulation results, new formulations of Burke-Turnbull and Hillert models are proposed. In contrast with classical formulations, the new ones account for the possible heterogeneity of the initial grain size distribution.
\end{abstract}

Keywords Grain growth · Mean field modeling · Full Field modeling · Level set

\section{Introduction}

Metallurgists have long observed that the macroscopic properties of the material, such as ductility, strength, thermal conductivity and hardness are strongly related to the microstructure, and especially to the mean grain size $(R)$. Thus, understanding the phenomenon of grain growth (GG) occurring after recrystallization is crucial for the optimization of the microstructure and the final in-use properties of the material.

Single-phase fully dense polycrystals can generally be described by a log-normal grain size distribution (GSD) Fatima Vaz and Fortes (1988); Raeisinia and Sinclair (2009); Luther and Könke (2009), defined by $(R)$ and a standard deviation $(\sigma)$. The standard deviation is related to the width of the grain radius dispersion around $(R)$. During grain growth mechanism, grain boundaries migrate under capillarity effects which results in an increase of $(R)$

\footnotetext{
L.M.MIRE

MINES ParisTech, PSL - Research University, CEMEF - Centre de mise en forme des matériaux, CNRS UMR 7635, CS 10207 rue Claude Daunesse 06904 Sophia Antipolis Cedex, France.

Tel.: +33652693656

E-mail: ludovic.maire@mines-paristech.fr

B.SChOltes $\cdot$ C.Moussa · N.Bozzolo ·D.Pino Muñoz ·M.BernaCKI

MINES ParisTech, PSL - Research University, CEMEF - Centre de mise en forme des matriaux, CNRS UMR 7635, CS 10207 rue Claude Daunesse 06904 Sophia Antipolis Cedex, France.
} 
and $\sigma$. A previous study has highlighted that the heterogeneity in terms of GSD in the microstructure at the early stages of grain growth may have a first-order influence on the overall kinetics Cruz-Fabiano et al (2014), but this work was only based on 2-D considerations.

Macroscopic models, also called mean field (MF) models, are widely used to describe the grain growth kinetics, mainly due to their low computational cost. These models are based on empirical or semi-empirical laws and require experimental investigations to calibrate fitting parameters. Furthermore given that these models are most of the time based on average fields (mean radius and mean curvature), they are not adapted for capturing heterogeneous phenomena such as abnormal grain growth.

Thanks to the increase in computer performances, finer approaches called full field (FF) models have emerged in the last decades. These approaches consider a complete description of the microstructure topology at the polycrystal scale. A review of the most significant numerical methods is given in Hallberg (2011). Probabilistic voxel-based approaches such as Monte Carlo Rollett et al (1989); Rollett and Raabe (2001); Holm et al (2001) and cellular automata Raabe (1999) are very popular. Another approaches found in the literature is the phase-field Krill and Chen (2002) method, which offers the advantage of avoiding the difficult problem of tracking the interfaces. Finally, grain growth can also be modeled using a level set description of the interfaces within a finite element framework Bernacki et al (2008, 2011); Scholtes et al (2015); Hallberg (2013), which is the full field method used in this work.

In this study we propose to quantify the influence of the initial GSD in the context of 3-D grain growth. More specifically, the predictions of the Hillert Hillert (1965) and BurkeTurnbull (B\&T) Burke and Turnbull (1952a) grain growth models are confronted with full field numerical simulations at the scale of a Representative Elementary Volume (REV) and under the assumptions of isotropic grain boundary energy and mobility, constant temperature and no precipitates. The digital initial microstructures are generated using a coupled "Vorono"1-Laguerre/dense sphere packing" algorithm Hitti et al (2012); Hitti and Bernacki (2013).

\section{Full field modeling of grain growth}

2.1 Material parameters and numerical tools

A $5 \mathrm{~h}$ heat treatment at a constant temperature of $1050^{\circ} \mathrm{C}$ for the austenitic $304 \mathrm{~L}$ steel is simulated. Isotropic values are considered for the grain boundary mobility $(M)$ and energy $(\gamma)$. More precisely the product $M Y$ is fixed to $8.2 \& 10^{-7} \mathrm{~J} . \mathrm{mm}^{-2}$, which is representative of a 304L stainless steel at $1050^{\circ} \mathrm{C} \mathrm{El} \mathrm{Wahabi} \mathrm{et} \mathrm{al} \mathrm{(2003);} \mathrm{Cruz-Fabiano} \mathrm{et} \mathrm{al} \mathrm{(2014).} \mathrm{The}$ material is assumed to be free of second phase particles (no Zener pinning effect).

The numerical simulations are performed on a cubic REV whose edge length varies from 2.00 to $2.85 \mathrm{~mm}$. Each simulation was performed on 60 Intel Xeon CPUs. An unstructured mesh composed of $292^{3}$ tetrahedral elements is used.

Eight different initial GSDs are considered to generate eight initial digital polycrystals. Each of them is defined by an initial mean grain radius $\left(R_{0}\right)$ and standard deviation $\sigma_{0}$. Their 
characteristics are summarized in table 1 (line 1-4). The distributions $\mathrm{LN}_{i}$ with $i \in\{1, \ldots$, follow a log-normal distribution. The last one, referred to as BiM, is bimodal with modes $\lambda_{1}=50 \mu \mathrm{m}$ and $\lambda_{2}=100 \mu \mathrm{m}$. The initial number of grains in the REV is close to 8000 while at least 1200 grains remain at the end of the heat treatment (see Tab. 1 and Fig. 3). The REV dimensions, the time steps and the mesh size are chosen so as to justify a good convergence of results in terms of grain boundary kinetics Scholtes et al $(2015,2016)$.

\begin{tabular}{llllllllll}
\hline & & $\mathrm{LN}_{1}$ & $\mathrm{LN}_{2}$ & $\mathrm{LN}_{3}$ & $\mathrm{LN}_{4}$ & $\mathrm{LN}_{5}$ & $\mathrm{LN}_{6}$ & $\mathrm{LN}_{\mathbf{7}}$ & $\mathrm{BiM}$ \\
\hline \hline$\left(R_{0}\right)$ & $(\mu \mathrm{m})$ & 62.0 & 66.0 & 74.3 & 75.3 & 82.2 & 89.4 & 99.0 & 75.2 \\
$\sigma_{0}$ & $(\mu \mathrm{m})$ & 6.90 & 11.8 & 19.4 & 7.50 & 25.9 & 30.9 & 17.7 & 25.5 \\
$\ln \left(\sigma_{0} /\left(R_{0}\right)\right)$ & & -2.20 & -1.71 & -1.35 & -2.30 & -1.14 & -1.05 & -1.71 & -1.08 \\
No. Grains & & 7920 & 7576 & 7474 & 8100 & 7460 & 7636 & 7588 & 7472 \\
\hline \hline \multicolumn{8}{c}{ Final state $(t=5 \mathrm{~h})$} \\
\hline$\left(R_{f}\right)$ & $(\mu \mathrm{m})$ & 109 & 120 & 135 & 111 & 151 & 160 & 138 & 115 \\
$\sigma_{f}$ & $(\mu \mathrm{m})$ & 39.0 & 45.0 & 53.2 & 39.8 & 59.9 & 66.3 & 50.7 & 36.0 \\
$\ln \sigma_{f} /\left(R_{f}\right)$ & & -1.03 & -0.98 & -0.93 & -1.03 & -0.92 & -0.88 & -1.00 & -1.16 \\
No. Grains & & 1483 & 1278 & 1244 & 2552 & 1221 & 1341 & 2803 & 2092 \\
\hline
\end{tabular}

Table 1: Characteristics of the initial (lines 1-4) and final (lines 5-8) GSDs predicted by the full field simulations.

\subsection{Full field simulation results}

An histogram representing the instantaneous GSD is generated every minute of the heat treatment simulation. Each histogram is composed of 30 equally spaced intervals delimited by 0 and $300 \mu \mathrm{m}$. Next the term distribution curve is introduced to denote a linear approximation of a GSD histogram. The objective of these distribution curves is to simplify the representation of the GSDs for future comparisons. Fig. 1 provides a schematic illustration of the distribution curve obtained by piecewise linear approximation of an histogram.

The figure 2 shows all the distribution curves predicted by the full field simulations for every initial GSDs at the early (solid curves) and final (dashed curves) stages of the simulation. These will be confronted with the Hillert model predictions in the next section.

Table 1 (line 5-8) presents the characteristics of the final GSDs predicted by the full field simulations. The ratio $\ln \left(\sigma_{f} \Lambda R\right)$ ) is observed to tend towards the value -1.00 after $5 \mathrm{~h}$ of treatment for every initial GSD. The figure 3 illustrates several REVs of full field simulations at the beginning and at the end of the heat treatment, for the $\mathrm{LN}_{1}$ and $\mathrm{BiM}$ initial GSDs. Among the REVs representing the log-normal GSDs, only the REV obtained for the $\mathrm{LN}_{1}$ initial GSD is depicted since this latter is representative of all the log-normal initial GSDs. A preponderant blue color is observed at the beginning of the heat treatment for the $\mathrm{LN}_{1}$ initial GSD, meaning that $\sigma_{0}$ is small for this distribution and most grains have sizes close to $R_{d}$. In the BiM initial GSD, two preponderant blue and green colors are observed in the REV at the beginning of the heat treatment. These two colors depict the two modes of the bimodal distribution, centered on grain size values of $50 \mu \mathrm{m}$ and $100 \mu \mathrm{m}$. 


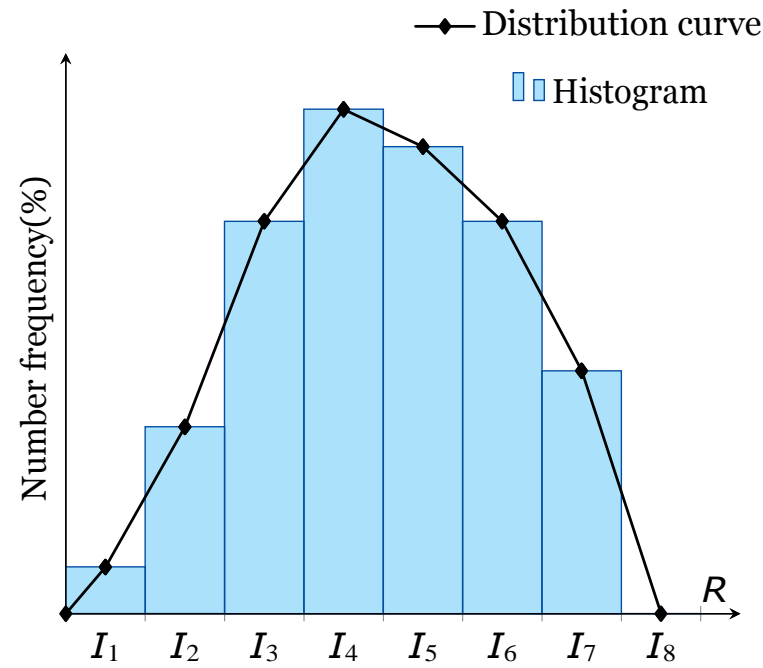

Fig. 1: Distribution curve obtained by linear approximation of an histogram

\section{Confrontations of full field simulation results with Hillert model}

\subsection{Hillert model}

In 1965, Hillert proposed a mean field model Hillert (1965) for normal grain growth. This model has already been discussed in many studies. Several authors, as in Darvishi Kamachali and Steinbach (2012); Darvishi Kamachali et al (2015); Suwa et al (2008); Rios et al (2006), recently confronted the predictions of this model with full field simulation results. Hillert model is considered to be more accurate than other grain growth models such as the one of B\&T Burke and Turnbull (1952b), since it is based on a discrete representation of the microstructure. This discrete microstructure is composed of $N$ classes of spherical grains having a radius $R_{i}(i \notin, \ldots, N\}$. Each class of grains evolves according to the following equation:

$$
\dot{R}_{i}=\beta M \gamma{\frac{1}{R_{\mathrm{cr}}}}^{-}{\frac{1}{R_{i}}}^{\Sigma},
$$

where $\dot{R}_{i}$ is the time derivative of $R_{i}$ and $R_{\text {cr }}$ is a critical grain radius. By applying the volume conservation in 3-D, it can be demonstrated that $R_{\text {cr }}=R^{2} X R$ Chao and Guoquan (2004); Rios et al (2006); Darvishi Kamachali et al (2015). For each initial GSD, the number of classes in the Hillert model has been taken equal to the number of grains in the REV of the corresponding full field simulation (see Tab. 1). The parameter $\beta$ is a geometrical dimensionless constant which refers to the inherent approximations concerning the assumed idealized geometry in the Hillert model representation. In $3-\mathrm{D}, \beta$ is assumed to be close to unity Hillert (1965). Other authors have nevertheless reported values above unity, such as $\beta$ C 1.25 Darvishi Kamachali and Steinbach (2012) and $\beta$ C 1.1 Suwa et al (2008). Darvishi 

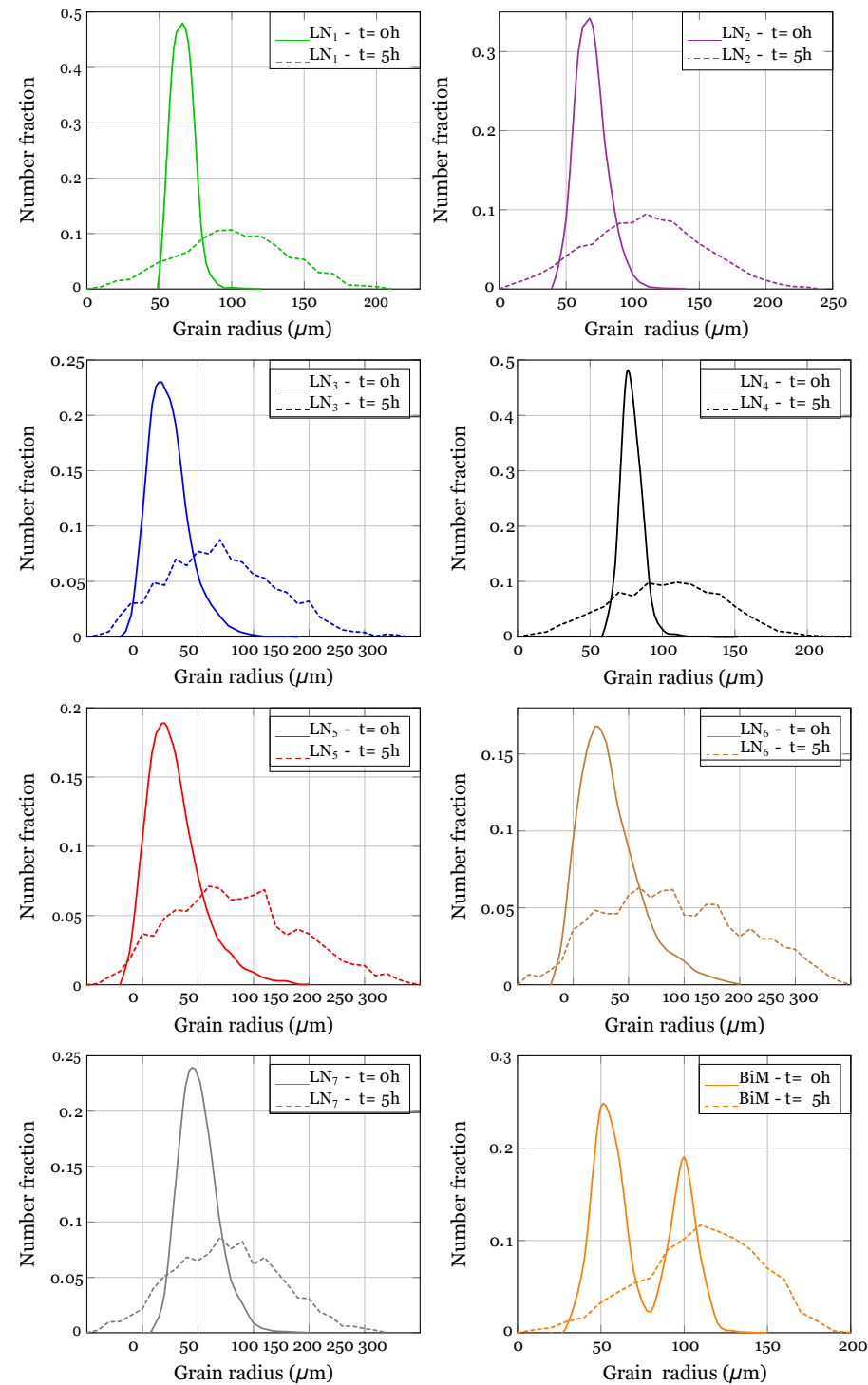

Fig. 2: Initial (solid curves) and final (dashed curves) distribution curves predicted by the full field simulations for the different initial GSDs.

Kamachali et al (2015) recently discussed a linear relationship valid in 3-D between the parameter $\beta$ and the index $(R) \mathcal{V}) R^{2}$ which aims to account for the geometrical relations between the neighbourhood grains for any given initial distribution.

Hereafter, the notation $\mathrm{Hi}(\beta)$ designates Eq. 1. So Hi(1) corresponds to the classical Hillert formulation Hillert (1965). As it employs several grain classes, this model has the advantage of being able to predict the GSD evolution in addition to the $(R)$ evolution. Previous works 


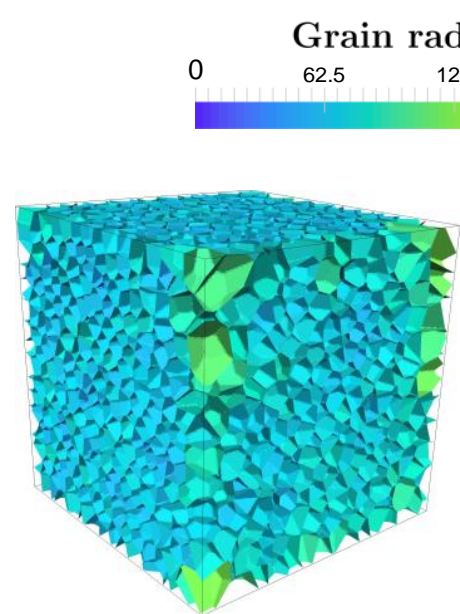

$\mathrm{LN}_{1} t=\mathrm{o} h$

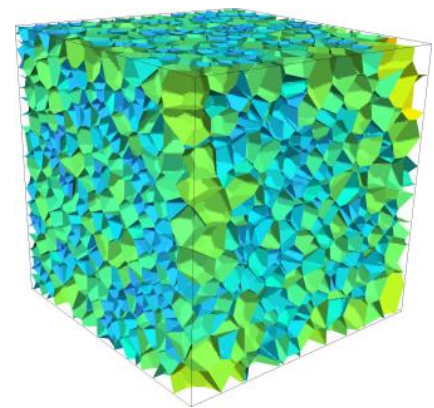

$\operatorname{BiM} t=\mathrm{o} h$

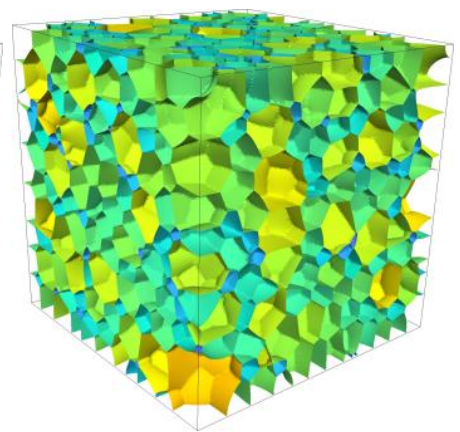

$\mathrm{LN}_{1} t=5 h$

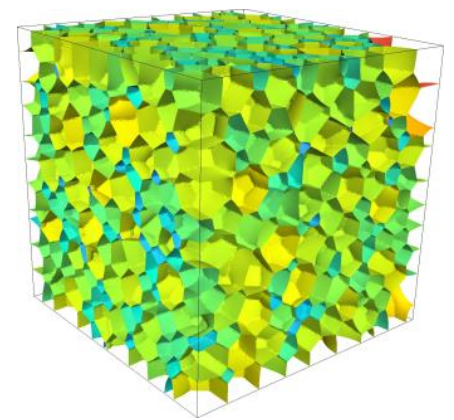

$\operatorname{BiM} t=5 h$

Fig. 3: Grain boundary networks at initial and final stages of the simulation for the $\mathrm{LN}_{1}$ and BiM initial GSDs. The color code corresponds to the equivalent sphere radius of each grain.

have shown the ability of the classical Hillert model to correctly capture the grain growth kinetics in 2-D for different initial GSDs Cruz-Fabiano et al (2014). In the same manner as for full field simulations, a GSD histogram is generated every minute of the Hillert simulation. The distribution curves are then deduced from the GSD histograms according to the method illustrated on Fig. 1. 


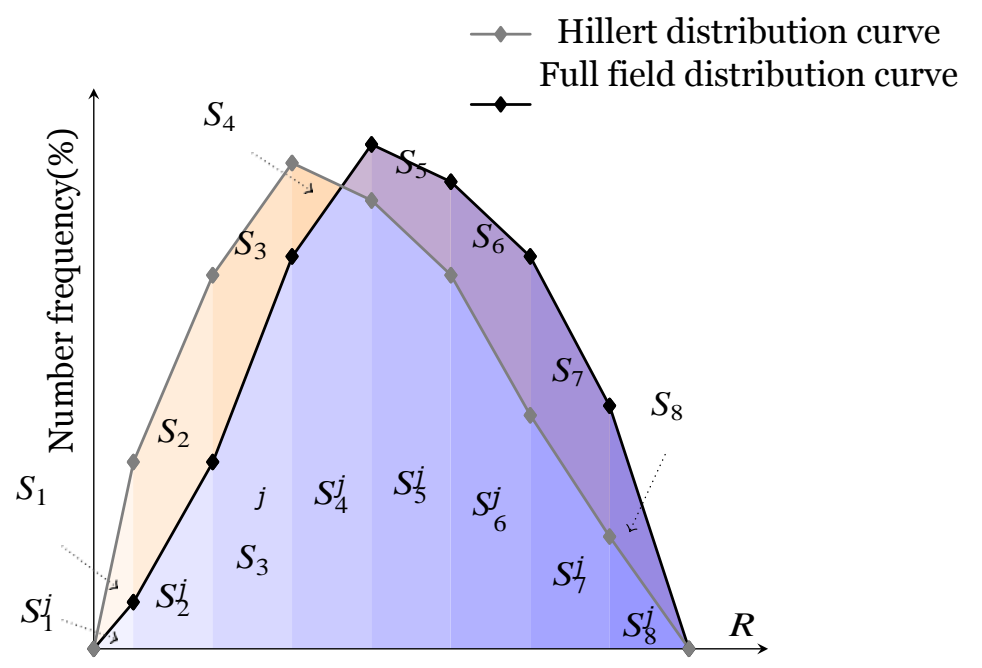

Fig. 4: Computed $L_{\mathrm{Hi}}^{2}$ error between the Hillert and full field distribution curve.

The notation $L_{\mathrm{H}}^{2}$ represents the instantaneous $L^{2}$ relative error measured between the distribution curves predicted by the Hillert and full field models. This quantity is computed as follows:

$$
\begin{aligned}
&\left.L^{2} \quad t\right)=100 \times-\overline{\sum_{i=1}^{N} \cdot S_{i}-S^{\mathrm{j}^{\Sigma_{2}}}}, \\
& \mathrm{Hi}\left(\quad \frac{i^{N}}{\sum_{i=1}^{N}\left(S_{i}^{\mathrm{j}}\right)^{2}}\right.
\end{aligned}
$$

where, as illustrated on Fig. 4, the distributions are approximated by a linear interpolation and $\mathrm{Si}$ (resp. Si') denotes the area of the i-th obtained trapezoid under the Hillert (resp. the full field) distribution curve. Hereafter the notation $\left(L_{\mathrm{Hi}}^{2}\right)$ designates the time average of the $L_{\mathrm{Hi}}^{2}(t)$ errors for a given simulation :

$$
\left(L_{\mathrm{Hi}}\right)=\varlimsup_{\mathrm{N}_{\text {incr }}} \sum L_{\mathrm{Hi}}(t),
$$

where $\mathrm{N}_{\text {incr }}$ is the number of time increments (equal to 300 in this study, $\mathrm{dt}=1 \mathrm{~min}$ ).

\subsection{Optimization of the Hillert model}

The values of $\left(L_{\mathrm{H}}^{2}\right.$ ) This error remains globally constant around $20 \%$ for all the initial GSDs. These results confirm the versatility of this model although a difference of $26 \%$ is observed for the $\mathrm{LN}_{4}$ and 


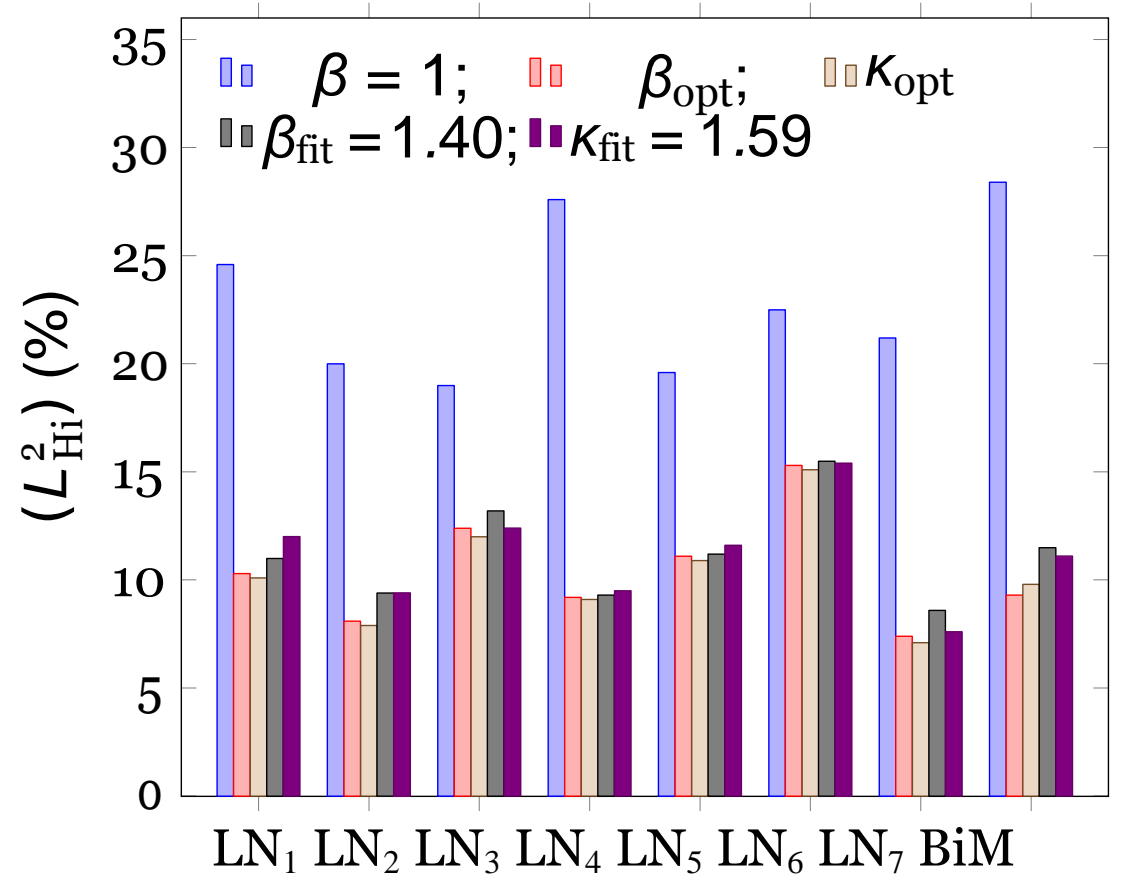

Fig. 5: Comparison in terms of $(L)^{2}$ error on the distribution curves predicted by the full field and Hillert models (see Eq. 2 for details).

BiM initial GSDs. The distribution curves predicted by the Hi(1) (blue curves) and the FF model (red curves) are also compared at different stages of the heat treatment on Fig. 7. The kinetic of grain growth obtained with the Hillert model seems to be slower than that obtained with the FF model. This is observable on Fig. 7 at each instant of the simulation by a time shift of the Hillert distribution curves with respect to the full field distribution curves.

As stated above, the value $\beta=1$ proposed by Hillert relies on many assumptions. For example Hillert consider that each shrinking grain has four immediate neighbours just before disappearing. Furthermore he considered that the $\beta$ value is two times larger in 3 -D than in 2-D where $\beta=0.5$ according to Hillert Hillert (1965). Although these assumptions are judicious and justified, we propose to recalibrated this Hillert parameter based on the results of the full field simulations. Thus, several Hillert calculations have been performed by varying the beta value from 0.5 to 2 by step of 0.01 . We denote $\beta_{\text {opt }}$ the value of $\beta$ in Eq. 1 that minimizes $\left(L_{\mathrm{Hi}}^{2}\right)$ error for each initial GSD. The values of $\beta_{\text {opt }}$ are provided in Tab. 2 . Red bars on Fig. 5 show the residual $L_{\mathrm{Hi}}$ error obtained with $\beta_{\mathrm{opt}}$. These residual errors have approximately been reduced by half compared to the classical value of $\beta$ equal to 1 . Furthermore the values of $\beta_{\text {opt }}$ are distributed around a mean value of 1.40 noted $\beta_{\text {fit }}$ (see green dots on Fig.6). 


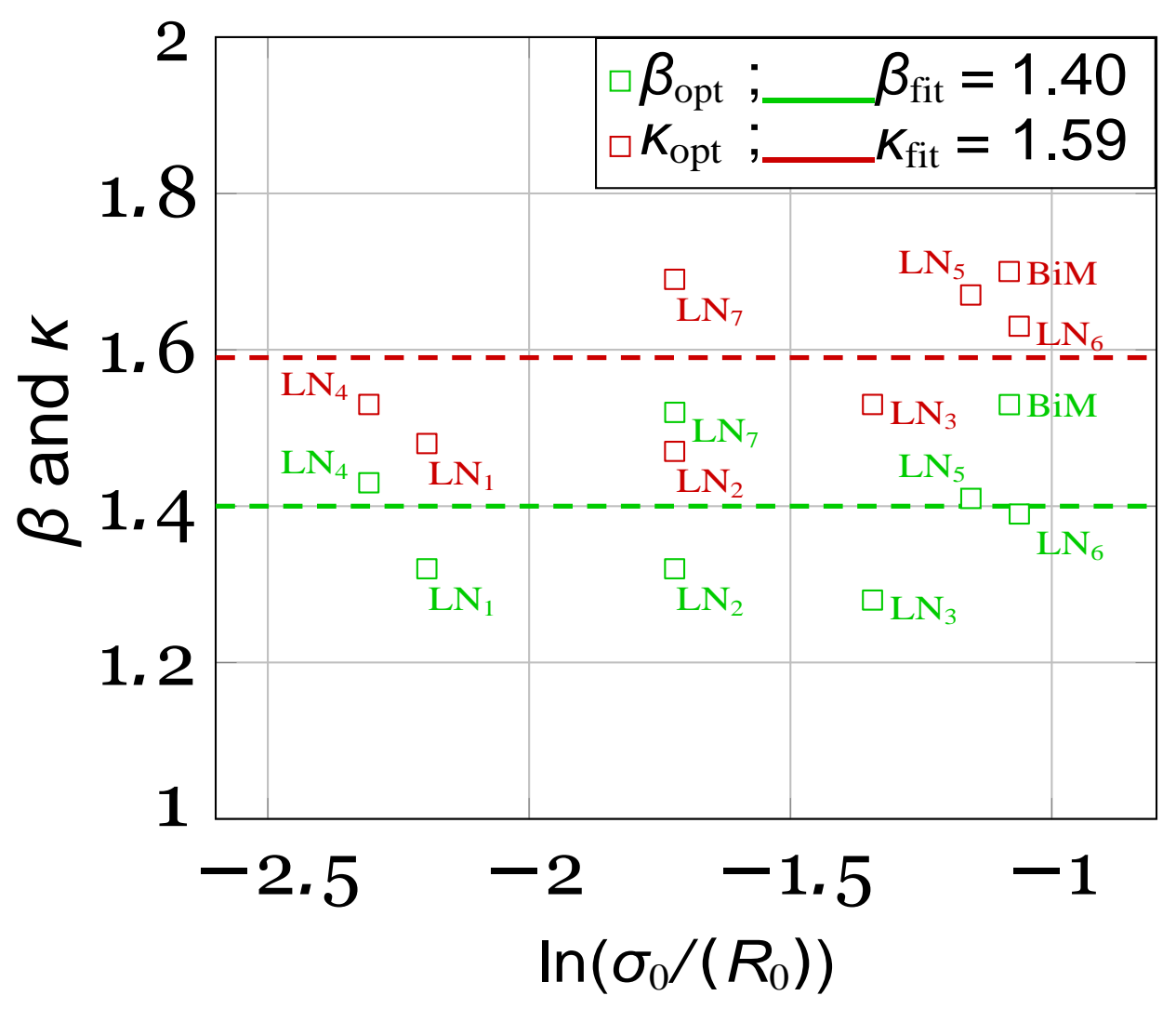

Fig. 6: Optimized values $\beta_{\mathrm{opt}}$ and $\kappa_{\mathrm{opt}}$ obtained by inverse analysis from the FF simulation results and fitting values $\beta_{\mathrm{fit}}$ and $\kappa_{\mathrm{fit}}$ obtained by an average of the optimized values.

To validate the calibrated value of $\beta=1.40$, the distribution curves predicted by the $\mathrm{Hi}(1.40)$ (green curves) and the full field models (red curves) are compared at different stages of the heat treatment on Fig. 7. It is worth noting that Hi(1.40) model provides non negligible improvements for the prediction of the GSDs compared to the initial Hi(1) model. Indeed, the time shift observed Fig. 7 between full field and $\mathrm{Hi}(1)$ distribution curves has been now rectified since this new value of $\beta=1.4$ is larger than the old one and thus logically increases the kinetic of grain growth. In a general way, the shapes of the GSDs are also in good agreement with the observation of Darvishi Kamachali and Steinbach (2012). GSDs are observed to be initially sharp and then become larger and larger during the heat treatment. After $2.5 \mathrm{~h}$ of treatment in the BiM initial case, one single peak is observed on the distribution curve, which means that the two modes merge in the first hours of the heat treatment.

In order to investigate further the theory of Darvishi Kamachali et al (2015), we define $\kappa_{0}$ as :

$$
\kappa_{0}=\frac{\beta_{\mathrm{opt}}}{(R)^{2} /\left(R^{2}\right)_{(t=0)}}
$$


where the index $(R)^{2} \bigvee R^{2}$ is taken at the instant $\mathrm{t}=0 \mathrm{~s}$ of the treatment. This choice has been done since this value does not significantly evolve during a simulation. The different values of $\kappa_{0}$ computed for every initial GSDs are provided in Line 3 of Tab. 2. These ratios are not constant between each initial GSDs, meaning that there is not a direct relation between $\beta$ and the index $(R)^{2} V R^{2}{ }_{(t=0)}$ for our cases. However this index, which considers the geometrical characteristics of neighbouring grains, could be useful to enrich the classical Hillert model (see Eq. 1).

Thus by replacing the $\beta$ parameter in Eq. 1 by the product of an assumed constant parameter noted $K$ times the ratio $(R)^{2} \bigvee \mathbb{R}^{2}$, we can consider the following Hillert model derived from the Darvishi Kamachali theory Darvishi Kamachali et al (2015):

$$
R_{i=} K_{\left(R^{2}\right)}{\frac{(R)^{2}}{R_{\mathrm{cr}}}}^{-}{\underline{R_{i}}}^{\prime}
$$

where $K$ is a constant parameter. We performed several Hillert calculations using this new formulation (see Eq. 5) and by varying the $K$ value from 1 to 2 with a step of 0.01 . We denote by $K_{\text {opt }}$ the value of $K$ that minimizes $\left(L^{2}\right)_{j}$ for each initial GSD. The $K_{\text {opt }}$ values are presented in Line 4 of Tab. 2 . Grey bars on Fig. 5 show the residual $E_{\mathrm{Hi}}$ error obtained with $\kappa_{\text {opt }}$. These residual errors are slightly little smaller than those obtdined with $\beta_{\text {opt }}$. However this difference is not significant enough to affirm that the model given by Eq. 5 gives better predictions than $\mathrm{Hi}(1.4)$ model. Furthemore the $\kappa_{\mathrm{opt}}$ values are distributed around a mean value of 1.59 noted $\kappa_{\text {fit }}$ (see red dots on Fig.6) resulting also in a lo(v $f_{\text {Hi }}^{2}$ ) error close to that obtained with the $\mathrm{Hi}\left(\beta_{\mathrm{fit}}\right)$ model (see purple bars on Fig. 5). These similar errors are logically due to the fact that the $\mathrm{Hi}(1.4)$ (Eq. 1) and the new Hillert formulation (Eq. 5) give very close predictions since the index $(R) \mathcal{V}) R^{2}$ does not change much during all our simulations. Finally, the distributions curves obtained according to the new Hillert formulation all overlay with those obtained according to the Hi(1.4) model.

\begin{tabular}{ccccccccc}
\hline & $\mathrm{LN}_{1}$ & $\mathrm{LN}_{2}$ & $\mathrm{LN}_{3}$ & $\mathrm{LN}_{4}$ & $\mathrm{LN}_{5}$ & $\mathrm{LN}_{6}$ & $\mathrm{LN}_{7}$ & $\mathrm{BiM}$ \\
\hline$\beta_{\text {opt }}$ & 1.32 & 1.32 & 1.28 & 1.43 & 1.41 & 1.39 & 1.52 & 1.53 \\
$\beta_{\text {fit }}$ & & & \multicolumn{9}{c}{1.40} \\
$\kappa_{0}$ & 1.35 & 1.36 & 1.38 & 1.43 & 1.57 & 1.58 & 1.57 & 1.72 \\
$\kappa_{\text {opt }}$ & 1.48 & 1.47 & 1.53 & 1.53 & 1.67 & 1.63 & 1.69 & 1.7 \\
$\kappa_{\text {fit }}$ & & \multicolumn{7}{c}{1.59} \\
\hline
\end{tabular}

Table 2: (Line 1-2) Optimized Hillert model parameter $\beta_{\text {opt }}$ calculated by inverse analysis from the full field simulation results (see eq. 1) and fitted Hillert model parameter $\beta_{\text {fit }}$ obtained by averaging the values of $\beta_{\text {opt }}$. (Line 3) Values of $\kappa_{0}$ defined as the ratio between $\beta_{\mathrm{opt}}$ and the initial index $(R) Z^{2} / R^{2}$ at time $=0$ s of every simulation. (Line 4-5) Optimized $K$ values $\left(K_{\text {opt }}\right)$ calculated by inverse analysis from the full field simulation results (see eq. $5)$ and fitted $K$ value $\left(\kappa_{\mathrm{fit}}\right)$ obtained by averaging the values of $\kappa_{\mathrm{opt}}$. 


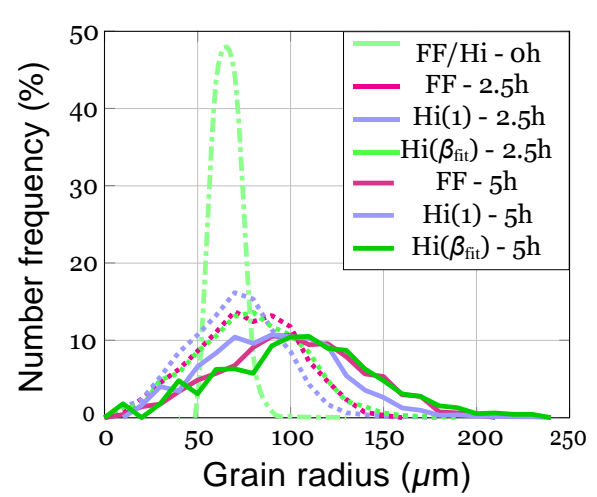

$\mathrm{LN}_{1}$

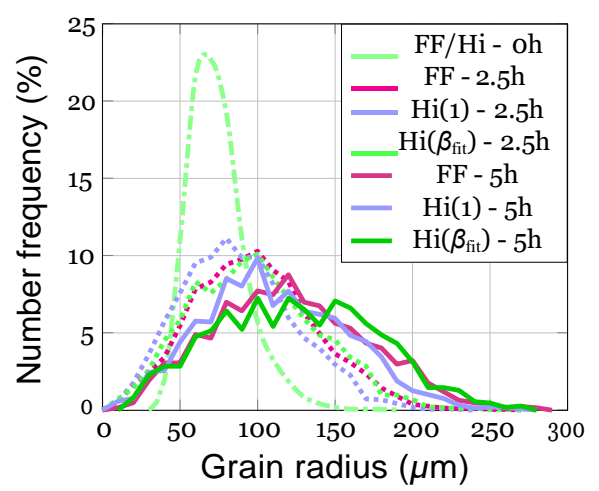

$\mathrm{LN}_{3}$

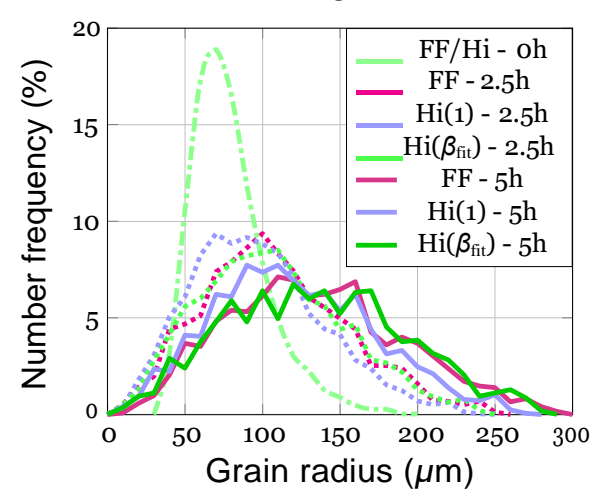

$\mathrm{LN}_{5}$

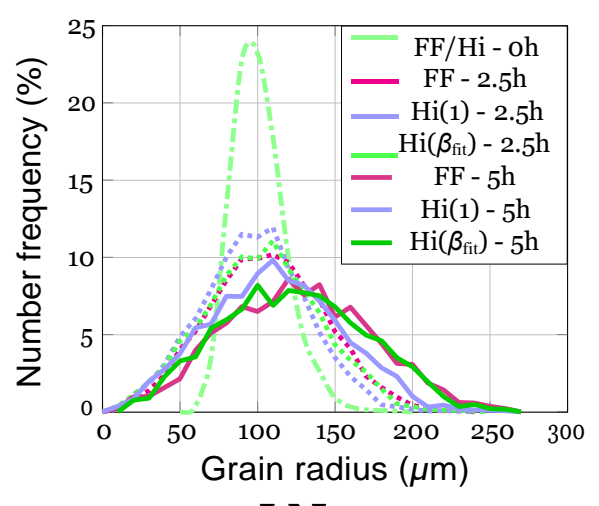

$\mathrm{LN}_{7}$

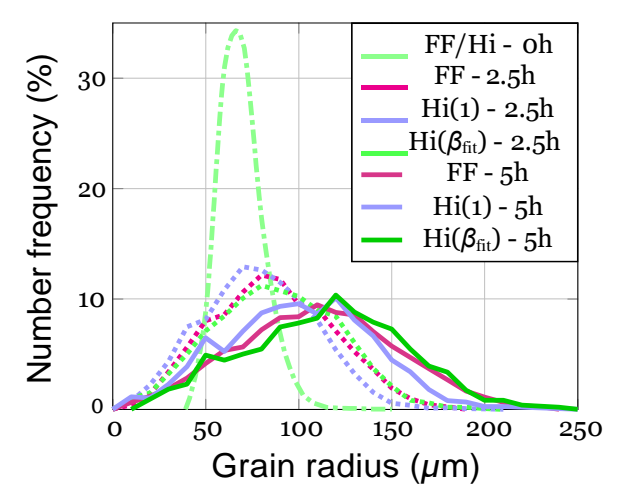

$\mathrm{LN}_{2}$

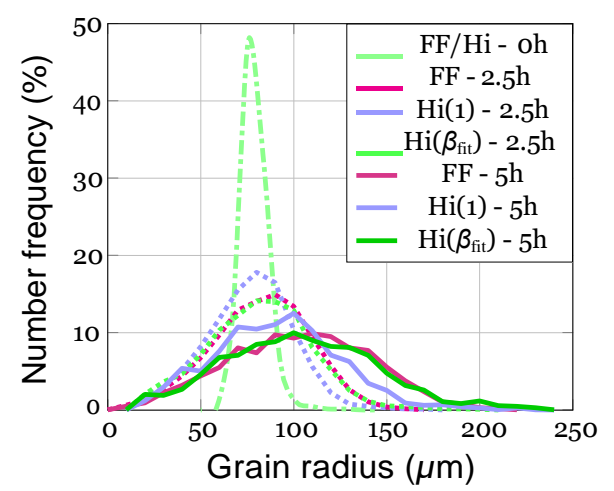

$\mathrm{LN}_{4}$

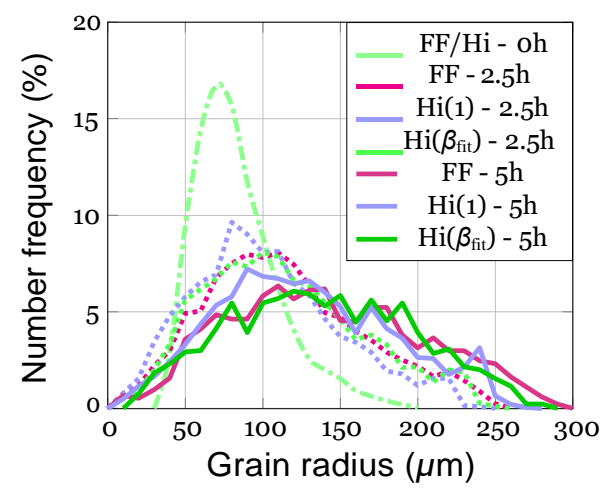

$\mathrm{LN}_{6}$

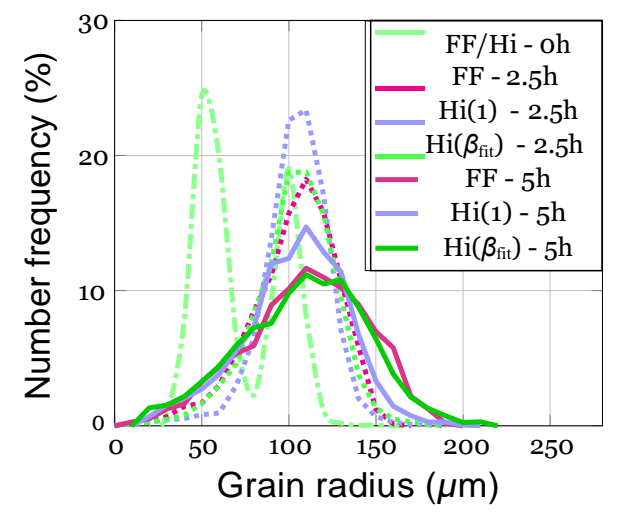

BiM

Fig. 7: Distribution curves predicted by the full field, $\mathrm{Hi}(1)$ and $\mathrm{Hi}(1.40)$ models for the different initial GSDs. 


\section{Confrontations of full field simulation results with $B \& T$ model}

\subsection{B\&T model}

For materials with a singlemode and uniform grain size, describing the evolution of $R$ ( ) could be sufficient as this quantity determines the global mechanical behavior of the material. Especially the Hall-Petch relationship states that the Yield stress of metallic materials can be expressed as a function of $(R)^{-0.5}$ Petch (1953). Furthermore in such cases, the initial GSD can be unknown and consequently the Hillert model can hardly be used. Thus, other mean field models can be used as a good alternative to describe the grain growth kinetics. In 1952, Burke and Turnbull (B\&T) investigated the physical mechanisms of grain growth. They particularly assumed that grain boundaries migrate by atom transport toward their center of curvature, under a force due to their curved shape. These findings gave rise to the B\&T model Burke and Turnbull (1952a), which predicts a parabolic evolution of ( $R$ as a function of the time $t$ :

$$
(R)^{2}-\left(R_{0}\right)^{2}=\delta M \gamma t,
$$

where $\delta=0.5$ according to Burke and Turnbull (1952a); Darvishi Kamachali and Steinbach (2012). This analytic mean field model has the advantage of being extremely simple to use since it requires only a value for the product $(M Y)$ and for the initial mean grain size $\left(R_{0}\right)$.

The predictions of the B\&T model will be confronted with the full field simulation results, using the following relative $L^{2}$ error:

$$
\begin{aligned}
L^{2} \% 100 \times & =\frac{\overline{\sum_{t=0}^{5 h}\left((R)_{\mathrm{FF}}(t)-(R)_{\mathrm{B} \& \mathrm{~T}}(t)\right)^{2}}}{\mathrm{~B} \& \mathrm{~T}()=} \\
& =\frac{\mathrm{FF}}{\sum_{t=0}^{5 h}(R)^{2}(t)}
\end{aligned}
$$

where $R_{\mathrm{B} \& \mathrm{~T}}$ and $R_{\mathrm{FF}}$ tepresent, respectively, the instantaneous values of $R$ (n the $\mathrm{B} \& \mathrm{~T}$ and full field models.

4.2 New formulation of the B\&T model

The resulting $L_{\mathrm{B} \& \mathrm{~T}}^{2}$ measured between the classical B\&T model predictions (Eq. 6) and the full field simulation results are illustrated by blue bars on Fig. 8. It is worth noting that these $L^{2}$ are smaller than the $\left(L^{2}\right)$ calculated in the previous section. Indeed $L^{2} \&$ relies on a single quantity which is the mean grain size of the material. On the other hand $\left(L_{\mathrm{Hi}}^{2}\right)$ rea single quantity which is the mean grain size of the material. On the other hand $\left(L_{\mathrm{Hi}}^{2}\right)$ re-
flects the difference of shape between the two distribution curves. Results show that $L_{\mathrm{B}}^{2}$ is
globally high for any initial case. Furthermore, $L^{2}$ globally high for any initial case. Furthermore, $L^{2}$ error globally increases when the ratio

$\sigma_{0} /\left(R_{0}\right)$ decreases. This finding is actually quite logical and can be easily explained. Indeed in the case of small $\sigma_{0} /\left(R_{0}\right)$ ratios, the grain boundary kinetic slows down at the early stages of the treatment because most grains have a initial radius close to $(R)$. Consequently theincrease of $(R)$ takes longer to initiate and a plateau or even a decrease could be observed at 


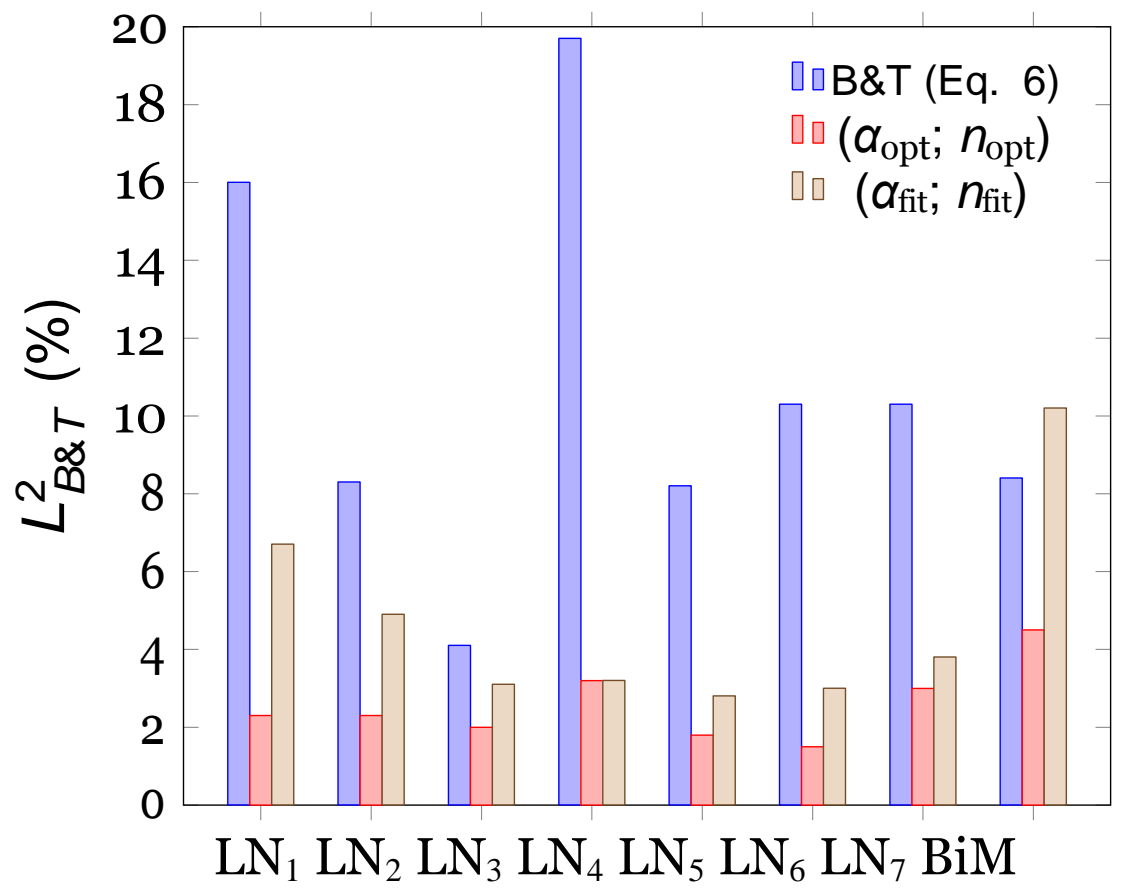

Fig. 8: Comparison in terms of $L^{2}$ error on the $(R)$ values predicted by the full field simulations and the different B\&T formulations (see Eq. 6 and Eq. 8 for more details).

the beginning of the thermal treatment. These typical evolutions occurring during the transient regime are not straightforward to capture with the classical B\&T model. Furthermore given that the transient regime can last few hours in some initial configurations, it cannot be neglected by the models. These results confirm the interest of improving the classical B\&T model. Recent numerical investigations in 2-D have also pointed out that B\&T model is not accurate for every $\sigma_{0} /\left(R_{0}\right)$ initial ratios Cruz-Fabiano et al(2014).

In order to make the classical B\&T formulation more accurate, the first objective is to determine whether there exists for each initial GSD, other $\delta$ values, noted $\delta_{\text {opt }}$, that correctly describe the grain growth kinetics. These $\delta_{\text {opt }}$ values are obtained by minimizing the $L_{\mathrm{B} \& \mathrm{~T}}^{2}$ for each initial GSD. The resulting fitting curves obtained by combining Eq. 6 and the $\delta_{\text {opt }}$ are depicted in Fig. 9 (dashed curves) for the $\mathrm{LN}_{4}$ and $\mathrm{LN}_{6}$ initial GSDs, which present the smallest and highest $\sigma_{0} /(R)_{b}$ ratios, respectively. It is observed that changing the values of $\delta$ does not correct the description of the transient regime. In particular for small $\sigma_{0} / R($ ) ratios, a model such as B\&T model cannot be accurate enough to describe these particular mean grain size evolutions.

In order to also check the consistency of this law in the steady-state regime, the curves $\log \left((R)^{2}(-) R_{0}{ }^{2}\right)=\mathrm{f}(\log (t))$ have been plotted on Fig. 10 according to full field results. A linear approximation of these curves is also added. We observed that the slopes of the linear 


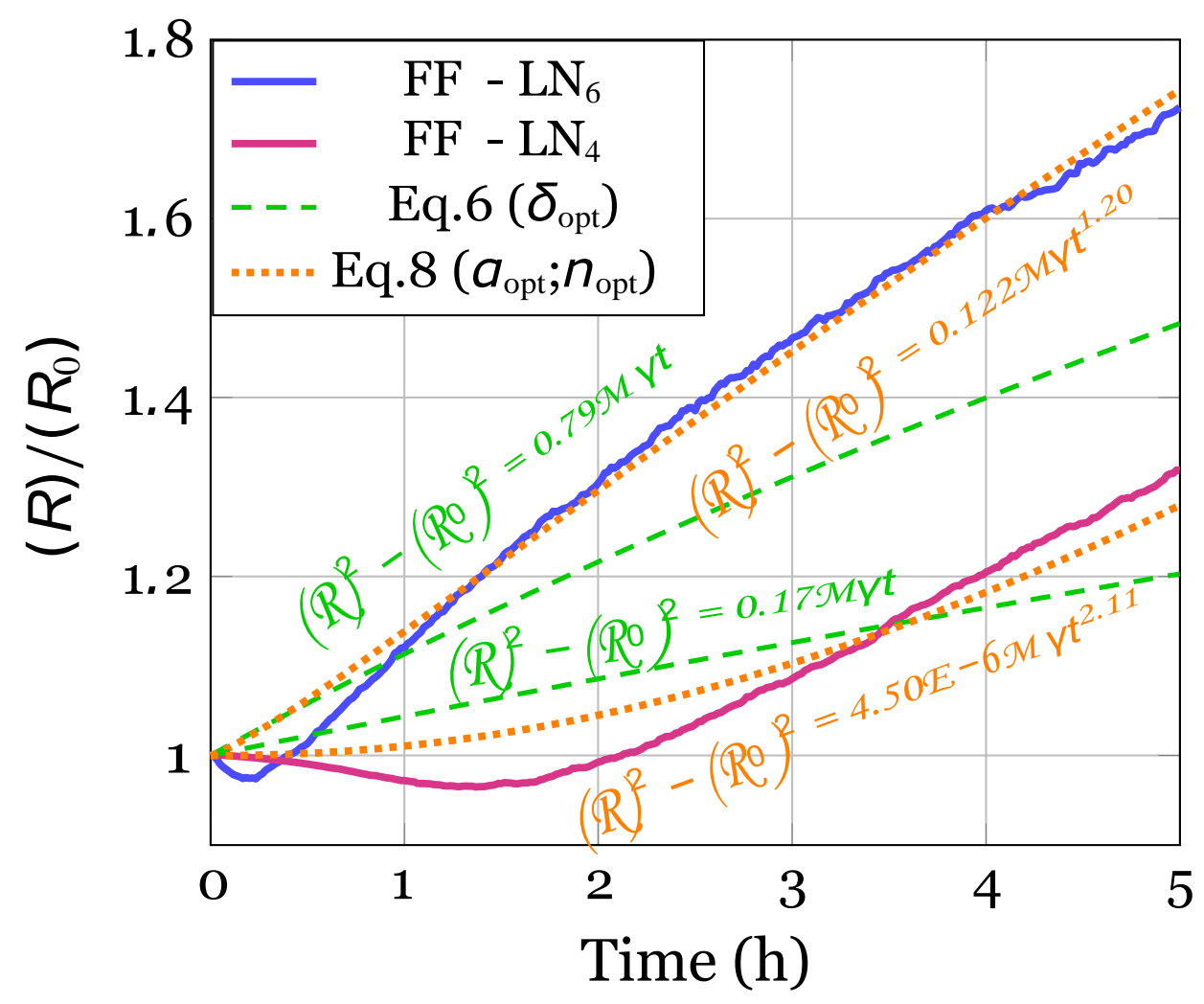

Fig. 9: Evolution of $(R) \wedge \mathbb{R}_{0}$ during the heat treatment. Solid curves corresponds to the full field results, dashed curves represent the B\&T predictions obtained by combining Eq. 6 and $\delta_{\text {opt }}$ and dotted curves represent the B\&T predictions obtained by combining Eq. 8 and the couple $\left(\alpha_{\text {opt }} ; n_{\text {opt }}\right)$.

approximations are quiet different for every initial GSD as already observed in the work of Cruz-Fabiano et al (2014), which means that the classical B\&T formulation cannot be sufficient to describe the kinetic of grain growth for every initial GSD.

Based on the previous observations, a new formulation of the B\&T model has been proposed in Cruz-Fabiano et al (2014) including a new fitting exponent $n$ aiming to take into account the different slopes observed on the Fig. 10 and the transient regimes observed on Fig. 9 :

$$
(R)^{2}-\left(R_{0}\right)^{2}=\alpha M y t^{n},
$$

where $\alpha$ is considered as a fitting parameter depending, in the same manner as the exponent $n$, on the initial GSD characteristics. Thus the validity of the classical B\&T model (see Eq. (6)) can be easily verified if the slope $n$ is equal to 1 and the fitted parameter $\alpha$ is equal to 0.5 . 


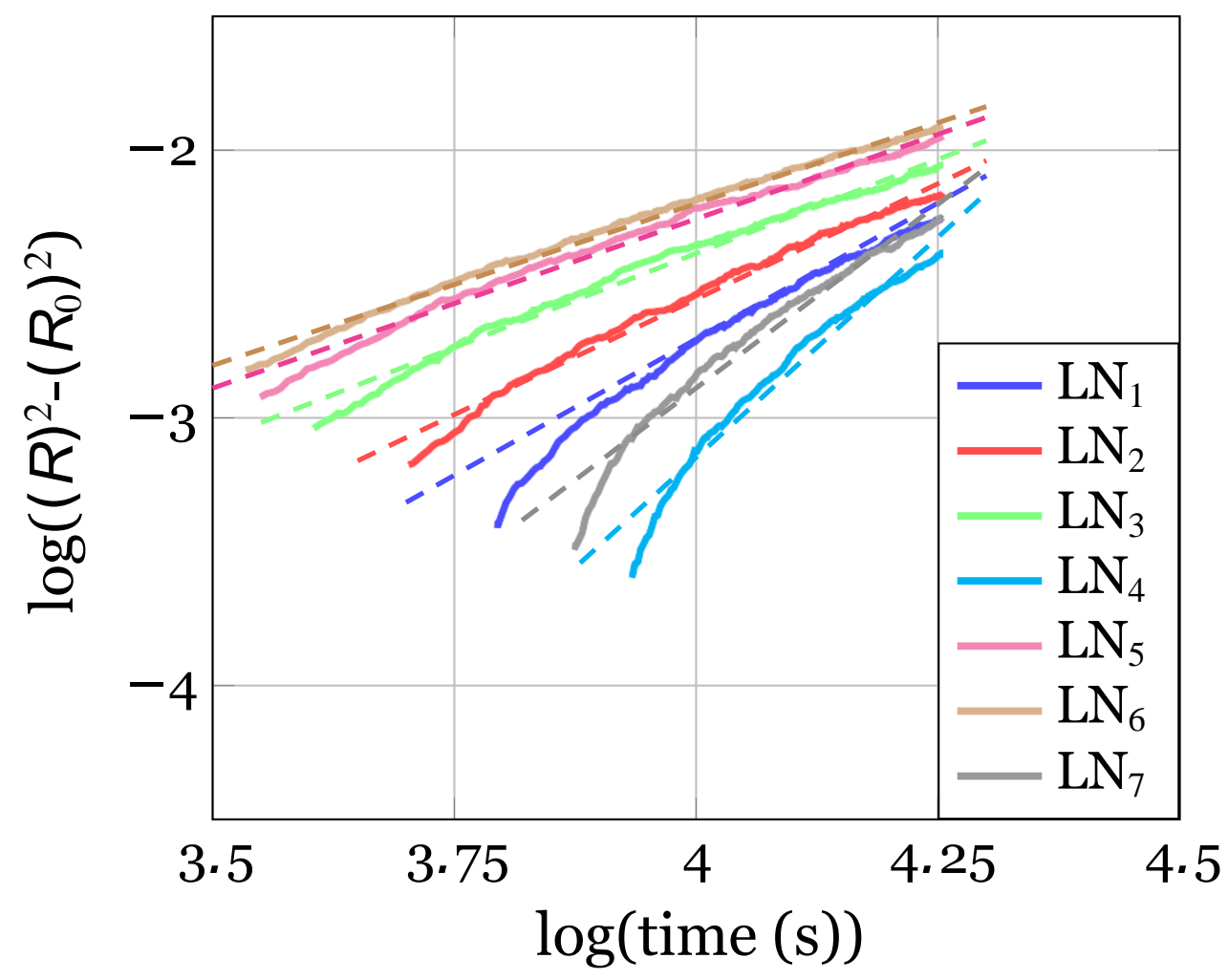

Fig. 10: Evolution of $\log \left((\mathrm{R})^{2}-\mathrm{R}_{0}{ }^{2}\right)$ as a function of $\log (\mathrm{t})$ during the steady state regimes according to full field results. Linear approximations are added in dashed line.

\begin{tabular}{lllllllll}
\hline & $\mathrm{LN}_{1}$ & $\mathrm{LN}_{2}$ & $\mathrm{LN}_{3}$ & $\mathrm{LN}_{4}$ & $\mathrm{LN}_{5}$ & $\mathrm{LN}_{6}$ & $\mathrm{LN}_{7}$ & $\mathrm{BiM}$ \\
\hline$\alpha_{\mathrm{opt}}$ & $6.20 \mathrm{e}-6$ & $6.00 \mathrm{e}-4$ & $1.66 \mathrm{e}-2$ & $4.50 \mathrm{e}-6$ & $7.45 \mathrm{e}-2$ & $1.22 \mathrm{e}-1$ & $6.18 \mathrm{e}-4$ & 35.0 \\
$n_{\text {opt }}$ & 2.13 & 1.69 & 1.37 & 2.11 & 1.24 & 1.20 & 1.64 & 0.56 \\
$\alpha_{\text {fit }}$ & $8.67 \mathrm{e}-6$ & $5.67 \mathrm{e}-4$ & $1.22 \mathrm{e}-2$ & $3.69 \mathrm{e}-6$ & $7.32 \mathrm{e}-2$ & $1.58 \mathrm{e}-1$ & $5.66 \mathrm{e}-4$ & $1.22 \mathrm{e}-1$ \\
$n_{\text {fit }}$ & 2.06 & 1.67 & 1.39 & 2.13 & 1.23 & 1.16 & 1.67 & 1.18 \\
$\ln \left(\sigma_{0}\left\langle\left(R_{0}\right)\right)\right.$ & -2.20 & -1.71 & -1.35 & -2.30 & -1.14 & -1.05 & -1.71 & -1.08 \\
\hline
\end{tabular}

Table 3: (line 1-2) Optimized B\&T model parameters $\alpha_{\mathrm{opt}}$ and $n_{\mathrm{opt}}$ obtained by inverse analysis from the full field simulation results (see Eq. 6) ; (line 3-4) Fitted mean field model parameters $\alpha_{\text {fit }}$ and $n_{\text {fit }}$ obtained by using the new formulations of Eq 9. (line 5) Ratio of the initial GSD characteristics.

Inverse analyses were performed in order to obtain optimal values of $\alpha_{\text {opt }}$ and $n_{\text {opt }}$ which minimize $L_{\mathrm{B} \& \mathrm{~T}}^{2}$. These values are plotted in Fig. 11 and the corresponding $L_{\mathrm{B} \& \mathrm{~T}}^{2}$ are illustrated by red bars on Fig. 8. Interestingly, the results of Tab. 3 and Fig. 8 show that there exists, for each initial distribution, a set of parameters $\left(\alpha_{\mathrm{opt}} ; n_{\mathrm{opt}}\right)$ which predicts very accurately the evolution of $(R)$, with $L_{\mathrm{B} \& \mathrm{~T}}^{2}<5 \%$. Furthermore the $\mathrm{LN}_{6}$ initial GSD presents the couple of parameters $\left(\alpha_{\mathrm{opt}} ; n_{\mathrm{opt}}\right)$ that is closest to the B\&T classical parameters $(\alpha=$ $0.5 ; n=1)$. This distribution has the largest ratio $\left(\sigma_{0} /\left(R_{0}\right) \subset 0.35\right)$ of this study. It is worth 
noting that increase the ratio $\sigma_{0} \Lambda \mathbb{R}_{0}$ should lead to a new couple of parameters $\left(\alpha_{\mathrm{opt}} ; n_{\mathrm{opt}}\right)$ even closer to the B\&T parameters. Cruz-Fabiano et al (2014) found in 2-D a couple parameters $\left(\alpha_{\mathrm{opt}} ; n_{\mathrm{opt}}\right)$ close to B\&T parameters for initial GSDs having a ratio $\sigma_{0} /\left(R_{0}\right) \subset 0.45$.

The predictions of $(R)$ obtained by combining Eq. 8 with the set of parameters $\left(\alpha_{\text {opt }} ; n_{\text {opt }}\right)$ have been plotted on the Fig. 9 (dotted curves) for the $\mathrm{LN}_{4}$ and $\mathrm{LN}_{6}$ initial GSDs. It is clearly observed that the resulting curves obtained with Eq. 8 (dotted curves) are closer to full field predictions than resulting curves obtained with Eq. 6 (dashed curves). However, the transient regime characterized by a decrease in $(R)$ during the first hour of treatment is not well described yet.

It is worth noting that the $\alpha_{\mathrm{opt}}$ and the $n_{\mathrm{opt}}$ values increase and decrease respectively with the $\sigma_{0} /\left(K_{0}\right.$ ratio (see Tab. 3). This trend has already been observed in the study proposed by Cruz-Fabiano et al (2014). These observations confirm that the ratio $\sigma_{0} \ell R_{0}$ is relevant for describing the evolution of $\alpha$ and $n$. Furthermore, the sets of parameters $\left(\alpha_{\mathrm{opt}} ; n_{\mathrm{opt}}\right)$ are observed to be quasi identical for the two $\mathrm{LN}_{2}$ and $\mathrm{LN}_{7}$ initial GSDs which present the same $\sigma_{0} /(R \phi)$ ratio. By plotting the parameters $\ln \left(\alpha_{\text {opt }}\right)$ and $n_{\text {opt }}$ as a function of the ra- tio $\ln \left(\sigma_{0} / R_{0}()\right)$ on Fig 11, two linear relationships can be deduced for the $n$ and $\alpha$ model parameters:

$$
\ln \left(\alpha_{\mathrm{fit}}\right)=8.53 \ln {\frac{\sigma_{0}}{\left(R_{0}\right)}}^{\Sigma}+7.11 \quad n_{\mathrm{fit}}=-0.78 \ln {\frac{\sigma_{0}}{\left(R_{0}\right)}}^{\Sigma}+0.34
$$

where these two constant parameters are quiet different from those obtained in Cruz-Fabiano et al (2014) probably due to the fact that this study is investigated in 3-D. Combining Eq. 8 and Eq. 9 results in the following improved B\&T formulation:

$$
(R)^{2}-\left(R_{0}\right)^{2}=1224.15{\frac{-\sigma_{0}}{\left(R_{0}\right)}}^{\Sigma_{8.53}} M^{-0.78 \ln t^{-}}{\frac{\sigma_{0}}{(R)_{0}}}^{\Sigma}+0.34
$$

Although the set $(\ln (\alpha)=3.56 ; n=0.56)$ obtained for the BiM initial GSD predicts well the evolution of $(R)$, it does not follow the trends obtained for the log-normal initial GSDs (see Fig. 11). So the formulation of the B\&T model given by Eq. 10 is only accurate for lognormal initial GSDs. By using $\alpha=\alpha_{\mathrm{fit}}$ and $n=n_{\mathrm{fit}}$ in Eq. 9 and 10 , small $L_{\mathrm{B} \& \mathrm{~T}}^{2}$ are obtained (see beige bars on Fig. 8 (b)). An interesting prospect of this study will be to perform the same analysis for different bimodal distributions. 


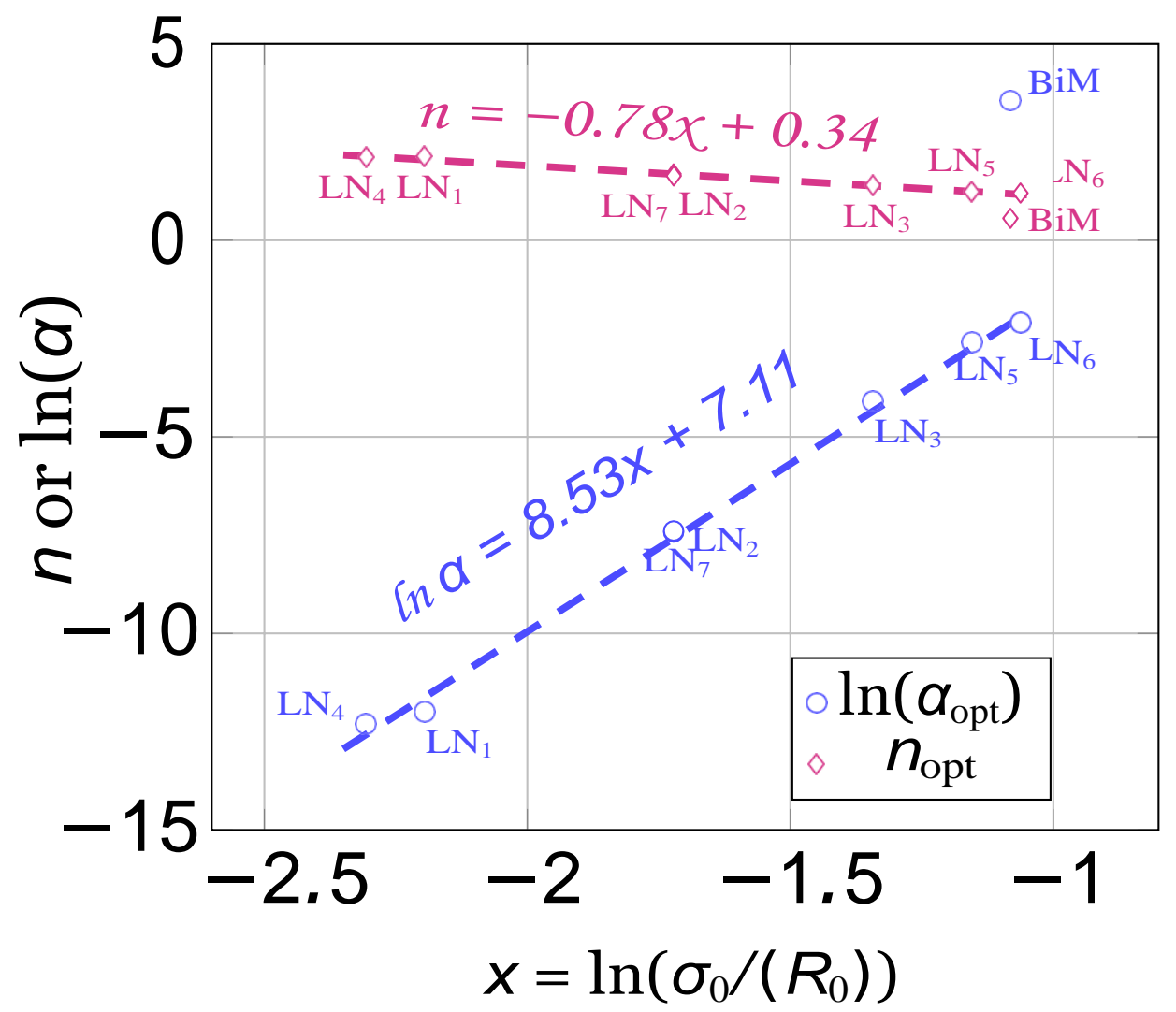

Fig. 11: Optimized values $\alpha_{\text {opt }}$ and $n_{\text {opt }}$ obtained by inverse analysis from the FF simulation results and linear relationships between the set of parameters $(\ln (\alpha) ; n)$ and the ratio $\ln \left(\sigma_{0} /\left(R_{0}\right)\right)$. 


\section{Conclusion}

The present study is devoted to the modeling of ideal grain growth phenomenon. More specifically, the Hillert and B\&T grain growth models have been confronted with large full field simulations at the polycrystal scale. These full field simulations are based on a level set method working within a finite element framework. Eight initial GSDs have been considered for the comparisons.

The Hillert model is shown to be versatile since it considers the initial GSD of the microstructure. However this model relies on a first-order parameter $\beta$ which needs to be finely calibrated. Numerical full field investigations have highlighted a new value for $\beta$, which is globally constant around 1.4 for all initial distributions. We have finally demonstrated that the calibrated Hillert model predicts finely $(R)$ and the evolution of the distribution curves, even for the BiM distribution.

The classical B\&T model does not take into account the initial GSD, which makes it inaccurate in many cases. Based on full field simulation results, a new B\&T formulation given in Eq. 9 has been proposed. This new formulation has been proven able to predict accurately the evolution of $(R)$ for any log-normal initial GSD, regardless of $\sigma_{0}$ and $(R)_{0}$. On the other hand, this new model is not universal and needs to be improved in order to consider other kinds of initial GSDs, like bimodal distributions.

Future work will be dedicated to (I) discuss the variability of the full field results obtained in comparison with the MacPherson-Srolovitz equation MacPherson and Srolovitz (2007) (II) perform additional simulations considering anisotropic grain boundary energy and/or mobility (III) complete the development of a full field model devoted to dynamic recrystallization (IV) perform the same kind of analysis in the context of the static and dynamic recrystallization phenomena $(\mathrm{V})$ perform experimental measurements to be compared with the newly proposed mean field formulations.

Conflict of Interest: The authors declare that they have no conflict of interest.

\section{References}

Abbruzzese G, Heckelmann I, Lücke K (1992) Statistical theory of two-dimensional grain growth. Acta Metall Mater 40(3):519-532

Agnoli A, Bozzolo N, Loge' RE, Franchet JM, Laigo J, Bernacki M (2014) Development of a level set methodology to simulate grain growth in the presence of real secondary phase particles and stored energy Application to a nickel-base superalloy. Computational Materials Science 89:233241, DOI 10.1016/j.commatsci.2014.03.054, URL http://linkinghub.elsevier.com/retrieve/ pii/S0927025614002158

Aldina S, AC F, MA F (1985) Computer simulation of grain growth in a bidimensional polycristal 19:14911496

Beltran O, Huang K, Loge' R (2015) A mean field model of dynamic and post-dynamic recrystallization predicting kinetics, grain size and flow stress. Computational Materials Science 102:293303, DOI 10.1016/j.commatsci.2015.02.043, URL http://linkinghub.elsevier.com/retrieve/ pii/S0927025615001445

Bernacki M, Chastel Y, Coupez T, Loge' R (2008) Level set framework for the numerical modelling of primary recrystallization in polycrystalline materials. Scripta Materialia 58(12):1129-1132, 
DOI 10.1016/j.scriptamat.2008.02.016, URL http://linkinghub.elsevier.com/retrieve/pii/ S1359646208001425

Bernacki M, Resk H, Coupez T,Loge'RE (2009) Finite element model of primary recrystallization in polycrystalline aggregates using a level set framework. Modelling and Simulation in Materials Science and Engineering 17(6):064,006, DOI 10.1088/0965-0393/17/6/064006, URL http://stacks.iop.org/ 0965-0393/17/i=6/a=064006?key=crossref.b10c4b90e783241fcb950f2c83e5932f

Bernacki M, Loge' R, Coupez T (2011) Level set framework for the finite-element modelling of recrystallization and grain growth in polycrystalline materials. Scripta Materialia 64(6):525-528, DOI 10.1016/j.scriptamat.2010.11.032, URL http://linkinghub.elsevier.com/retrieve/pii/ S1359646210007906

Bernard P, Bag S, Huang K, Loge' R (2011) A two-site mean field model of discontinuous dynamic recrystallization. Materials Science and Engineering: A 528(24):7357-7367, DOI 10.1016/j.msea.2011.06.023, URL http://linkinghub.elsevier.com/retrieve/pii/S0921509311006757

Bulatov VV, Reed BW, Kumar M (2013) Grain boundary energy function for fcc metals. Acta Materialia 65:161-175, DOI 10.1016/j.actamat.2013.10.057, URL http://dx.doi.org/10.1016/j.actamat. 2013.10.057

Burke J, Turnbull D (1952a) Recrystallization and grain growth. Prog Met Phys 3:220

Burke J, Turnbull D (1952b) Recrystallization and grain growth. Progress in Metal Physics 3:220-292, DOI $10.1016 / 0502-8205(52) 90009-9$

Chao W, Guoquan LIU (2004) Reanalysis of the 3D quasi-stationary grain size distribution based on Hillert grain growth rate equation. Ser E Technological Sciences 47(1):112-120

Chen F, Cui Z, Chen J (2014) Prediction of microstructural evolution during hot forging. Manufacturing Review 1:6, DOI 10.1051/mfreview/2014006, URL http://mfr.edp-open.org/10.1051/mfreview/ 2014006

Cram DG, Zurob HS, Brechet YJM, Hutchinson CR (2009) Modelling discontinuous dynamic recrystallization using a physically based model for nucleation. Acta Materialia 57(17):5218-5228, DOI 10.1016/j.actamat.2009.07.024, URL http://dx.doi.org/10.1016/j.actamat.2009.07.024

Cruz-Fabiano A, Loge' R, Bernacki M (2014) Assessment of simplified 2D grain growth models from numerical experiments based on a level set framework. Computational Materials Science 92:305312, DOI 10.1016/j.commatsci.2014.05.060, URL http://linkinghub.elsevier.com/retrieve/ pii/S0927025614003863

Darvishi Kamachali R, Steinbach I(2012)3-D phase-field simulation of grain growth: Topological analysis versus mean-field approximations. Acta Materialia 60(6-7):2719-2728, DOI 10.1016/j.actamat.2012.01. 037, URL http://dx.doi.org/10.1016/j.actamat.2012.01.037

Darvishi Kamachali R, Abbondandolo A, Siburg KF, Steinbach I(2015) Geometrical grounds of mean field solutions for normal grain growth. Acta Materialia 90:252-258, DOI 10.1016/j.actamat.2015.02.025, URL http://dx.doi.org/10.1016/j.actamat.2015.02.025

Dehghan-Manshadi A, Barnett M. Hodgson P (2008) Recrystallization in AISI 304 austenitic stainless steel during and after hot deformation. Materials Science and Engineering: A 485(1-2):664672, DOI 10.1016/j.msea.2007.08.026, URL http://linkinghub.elsevier.com/retrieve/pii/ S0921509307015626

Ding R, Guo ZX (2001) Coupled quantitative simulation of microstructural evolution and plastic flow during dynamic recrystallization. Acta Materialia 49(16):3163-3175, DOI 10.1016/S1359-6454(01)00233-6

El Wahabi M, Cabrera J, Prado J (2003) Hot working of two AISI 304 steels: a comparative study. Materials Science and Engineering: A 343(1-2):116-125, DOI 10.1016/S0921-5093(02)00357-X, URL http: //www.sciencedirect.com/science/article/pii/S092150930200357X

Elsey M, Esedo[gbar]lu S, Smereka P (2011a) Large-scale simulations and parameter study for a simple recrystallization model. Philosophical Magazine 91(11):1607-1642, DOI 10.1080/14786435.2010.546377 Elsey M, Esedoglu S, Smereka P (2011b) Large-scale simulation of normal grain growth via diffusiongenerated motion. Proceedings of the Royal Society A: Mathematical, Physical and Engineering Sciences 467(2126):381-401, DOI 10.1098/rspa.2010.0194

Esche S (2011) Monte Carlo Simulations of Grain Growth in Metals. Applications of Monte Carlo Method in Science and Engineering (Cmc):581610, DOI 10.5772/14942, URL http://cdn.intechopen.com/pdfs/14026/ InTechMonte\{_\}carlo\{_\}simulations \{\}$\left._{-}\right\}$of $\left\{_{-}\right\}$grain $\left\{_{-}\right\}$growth $\left\{_{-}\right\}$in \{\}$\left._{-}\right\}$metals.pdf

Esedolu S (2016) Grain size distribution under simultaneous grain boundary migration and grain rotation in two dimensions. Computational Materials Science 121:209-216, DOI 10.1016/j.commatsci.2016.04. 022, URL http://linkinghub.elsevier.com/retrieve/pii/S0927025616301811

Fan XG, Yang H, Sun ZC, Zhang DW (2010) Quantitative analysis of dynamic recrystallization behavior using a grain boundary evolution based kinetic model. Materials Science \& Engineering A 
527(21-22):5368-5377, DOI 10.1016/j.msea.2010.05.032, URL http://dx.doi.org/10.1016/j. msea.2010.05.032

Fatima Vaz M, Fortes M (1988) Grain size distribution : The lognormal and the gamma distribution functions. Pergamon journals 22:35-40

Favre J, Fabrègue D, Chiba A, Bréchet Y (2013) Nucleation of recrystallization in fine-grained materials: an extension of the BaileyHirsch criterion. Philosophical Magazine Letters 93(11):631-639, DOI 10.1080/09500839.2013.833352, URL http://www.tandfonline.com/doi/abs/10.1080/ 09500839.2013.833352

Hallberg H (2011) Approaches to Modeling of Recrystallization. Metals 1(1):16-48, DOI 10.3390/ met1010016, URL http://www.mdpi.com/2075-4701/1/1/16/

Hallberg H (2013) A modified level set approach to 2D modeling of dynamic recrystallization. Modelling and Simulation in Materials Science and Engineering 21(8):085,012, DOI 10.1088/0965-0393/21/8/085012, URL http://stacks.iop.org/0965-0393/21/i=8/a=085012? $\mathrm{key}=$ crossref.fc2d86d9805f0075a83535b0524735cb

Hallberg H, Wallin M, Ristinmaa M (2010) Simulation of discontinuous dynamic recrystallization in pure $\mathrm{Cu}$ using a probabilistic cellular automaton. Computational Materials Science 49(1):2534, DOI 10.1016/j.commatsci.2010.04.012, URL http://linkinghub.elsevier.com/retrieve/ pii/S0927025610002259

Hillert M (1965) On the theory of normal and abnormal grain growth. Acta Metall Mater 13:227, DOI 10.1017/CBO9781107415324.004, arXiv:1011.1669v3

Hitti K, Bernacki M (2013) Optimized Dropping and Rolling (ODR) method for packing of poly-disperse spheres. Applied Mathematical Modelling 37(8):5715-5722, DOI 10.1016/j.apm.2012.11.018, URL http://dx.doi.org/10.1016/j.apm.2012.11.018

Hitti K, Laure P,CoupezT,Silva L, Bernacki M(2012) Precise generation of complex statistical Representative Volume Elements (RVEs) in a finite element context. Computational Materials Science 61:224-238, DOI 10.1016/j.commatsci.2012.04.011, URL http://dx.doi.org/10.1016/j.commatsci.2012. 04.011

Holm EA, Hassold GN, Miodownik MA (2001) On misorientation distribution evolution during anisotropic grain growth. Acta Materialia 49(15):2981-2991, DOI 10.1016/S1359-6454(01)00207-5

Jafari M, Najafizadeh A (2009) Correlation between Zener Hollomon parameter and necklace DRX during hot deformation of 316 stainless steel. Materials Science and Engineering 501:16-25, DOI 10.1016/j. msea.2008.09.073

Jonas JJ, Quelennec X, Jiang L (2009) The Avrami kinetics of dynamic recrystallization. Acta Materialia 57:2748-2756, DOI 10.1016/j.actamat.2009.02.033

Khoddam S, Hodgson P,Beladi H (2015) Computational inverse analysis of static recrystallization kinetics. International Journal of Mechanical Sciences 103:97-103, DOI 10.1016/j.ijmecsci.2015.09.008, URL http://linkinghub.elsevier.com/retrieve/pii/S0020740315003264

Kim BN, Hiraga K, Morita K (2004) Kinetics of normal grain growth depending on the size distribution of small grains. Nippon Kinzoku Gakkaishi/Journal of the Japan Institute of Metals 68(10):913-918, DOI 10.2320/matertrans.44.2239

Kim Si, Yoo Yc (2001) Dynamic recrystallization behavior of AISI 304 stainless steel. Materials Science and Engineering 311:108-113

Krill CE, Chen LQ (2002) Computer simulation of 3-D grain growth using a phase-field model. Acta Materialia 50(12):3059-3075, DOI 10.1016/S1359-6454(02)00084-8, URL http://www.sciencedirect. com/science/article/B6TW8-466R5TY-1/2/4e83847503c9ca5646b71d4de608f2fa

Lazar EA, Mason JK, MacPherson RD, Srolovitz DJ (2011) A more accurate three-dimensional grain growth algorithm. Acta Materialia 59(17):6837-6847, DOI 10.1016/j.actamat.2011.07.052, URL http://dx. doi.org/10.1016/j.actamat.2011.07.052

Li X, Duan L, Li J, Wu X (2015) Experimental study and numerical simulation of dynamic recrystallization behavior of a micro-alloyed plastic mold steel. Materials and Design 66:309-320, DOI 10.1016/j.matdes. 2014.10.076, URL http://dx.doi.org/10.1016/j.matdes.2014.10.076

Lin Y,Chen XM (2011) A critical review of experimental results and constitutive descriptions for metals and alloys in hot working. Materials \& Design 32(4):1733-1759, DOI 10.1016/j.matdes.2010.11.048, URL http://www.sciencedirect.com/science/article/pii/S0261306910006746

Lücke K, Brandt R (1998) Normal and Abnormal Grain Growth as Transient Phenomena 6:67-76

Lücke K, Heckelmann I, Abbruzzese G (1992) Statistical theory of two-dimensional grain growthII. Kinetics of grain growth. Acta Metallurgica et Materialia 40(3):533-542, DOI 10.1016/0956-7151(92)90402-Z, URL http://www.sciencedirect.com/science/article/pii/095671519290402Z

Luther T, Könke C (2009) Polycrystal models for the analysis of intergranular crack growth in metallic materials. Engineering Fracture Mechanics 76(15):2332-2343, DOI 10.1016/j.engfracmech.2009.07.006, 
URL http://dx.doi.org/10.1016/j.engfracmech.2009.07.006

MA(1939) Kinetics of Phase Change I-III.J Chem Physics 7:1103-1112

MacPherson RD, Srolovitz DJ (2007) The von Neumann relation generalized to coarsening of threedimensional microstructures. Nature 446(7139):1053-1055, DOI 10.1038/nature05745

MadejL,SitkoM,PietrzykM(2016) Perceptive comparison of mean and fullfield dynamic recrystallization models. Archives of Civil and Mechanical Engineering 16(4):569-589, DOI 10.1016/j.acme.2016.03. 010, URL http://linkinghub.elsevier.com/retrieve/pii/S1644966516300115

Miodownik Ma (2002) A review of microstructural computer models used to simulate grain growth and recrystallisation in aluminium alloys. Journal of Light Metals 2(3 SPEC.):125-135, DOI 10.1016/ S1471-5317(02)00039-1

Mirzadeh H (2015) Constitutive modeling and prediction of hot deformation flow stress under dynamic recrystallization conditions. Mechanics of Materials 85:66-79, DOI 10.1016/j.mechmat.2015.02.014, URL http://linkinghub.elsevier.com/retrieve/pii/S0167663615000617

Momeni A, Dehghani K, Ebrahimi GR (2011) Modeling the initiation of dynamic recrystallization using a dynamic recovery model. Journal of Alloys and Compounds 509(39):9387-9393, DOI 10.1016/j.jallcom. 2011.07.014, URL http://dx.doi.org/10.1016/j.jallcom.2011.07.014

Montheillet F, Lurdos O, Damamme G (2009) A grain scale approach for modeling steady-state discontinuous dynamic recrystallization. Acta Materialia 57(5):1602-1612, DOI 10.1016/j.actamat.2008.11.044, URL http://linkinghub.elsevier.com/retrieve/pii/S1359645408008641

Olmsted DL, Holm EA, Foiles SM (2009) Survey of computed grain boundary properties in face-centered cubic metalsII: Grain boundary mobility. Acta Materialia 57(13):3704-3713, DOI 10.1016/j.actamat.2009. 04.015, URL http://www.sciencedirect.com/science/article/pii/S1359645409002316

Petch N (1953) The cleavage strength of polycrystals. J Iron Steel Inst 174:25

Piekos' K, Tarasiuk J, Wierzbanowski K, Bacroix B (2008) Generalized vertex model of recrystallization Application to polycrystalline copper. Computational Materials Science 42(4):584-594, DOI 10.1016/j. commatsci.2007.09.014

Raabe D (1999) Introduction of a scalable three-dimensional cellular automaton with a probabilistic switching rule for the discrete mesoscale simulation of recrystallization phenomena. Philosophical Magazine A 79(10):2339-2358, DOI 10.1080/01418619908214288, URL http://www.tandfonline.com/doi/ abs/10.1080/01418619908214288

Raeisinia B, Sinclair CW (2009) A representative grain size for the mechanical response of polycrystals. Materials Science and Engineering A 525(1-2):78-82, DOI 10.1016/j.msea.2009.06.045

Rios PR, Dalpian TG, Brandao VS, Castro JA, Oliveira ACL (2006) Comparison of analytical grain size distributions with three-dimensional computer simulations and experimental data. Scripta Materialia 54(9):1633-1637, DOI 10.1016/j.scriptamat.2006.01.007

Rollett AD (1997) Overview of modeling and simulation of recrystallization. Progress in Materials Science 42(1-4):79-99, DOI 10.1016/S0079-6425(97)00008-X

Rollett AD, Raabe D (2001) A hybrid model for mesoscopic simulation of recrystallization. Computational Materials Science 21(1):69-78, DOI 10.1016/S0927-0256(00)00216-0, URL http://www. sciencedirect.com/science/article/pii/S0927025600002160

Rollett AD, Srolovitz DJ, Anderson MP (1989) Simulation and theory of abnormal grain growthanisotropic grain boundary energies and mobilities. Acta Metallurgica 37(4):1227-1240, DOI 10.1016/ 0001-6160(89)90117-X

Roucoules C, Pietrzyk M, Hodgson PD (2003) Analysis of work hardening and recrystallization during the hot working of steel using a statistically based internal variable model. Materials Science and Engineering A 339(1-2):1-9, DOI 10.1016/S0921-5093(02)00120-X

Sakai T, Belyakov A, Kaibyshev R, Miura H, Jonas JJ (2014) Dynamic and post-dynamic recrystallization under hot, cold and severe plastic deformation conditions. Progress in Materials Science 60:130_ 207, DOI 10.1016/j.pmatsci.2013.09.002, URL http://linkinghub.elsevier.com/retrieve/ pii/S0079642513000698

Scholtes B, Shakoor M, Settefrati A, Bouchard PO, Bozzolo N, Bernacki M (2015) New finite element developments for the full field modeling of microstructural evolutions using the level-set method. Computational Materials Science 109:388-398, DOI 10.1016/j.commatsci.2015.07.042, URL http: //linkinghub.elsevier.com/retrieve/pii/S0927025615004528

Scholtes B, Boulais-sinou R, Settefrati A, Pino Muñoz D, Poitrault I, Montouchet A, Bozzolo N, Bernacki M (2016) 3D level set modeling of static recrystallization considering stored energy fields. Computational Materials Science

Shakoor M, Scholtes B, Bouchard PO, Bernacki M (2015) An efficient and parallel level set reinitialization method Application to micromechanics and microstructural evolutions. Applied Mathematical Modelling DOI 10.1016/j.apm.2015.03.014, URL http://linkinghub.elsevier.com/retrieve/pii/ 
S0307904X15001638

Suwa Y, Saito Y, Onodera H (2008) Parallel Computer Simulation of Three-Dimensional Grain Growth Using the Multi-Phase-Field Model. Materials Transactions 49(4):704-709, DOI 10.2320/matertrans. MRA2007225

Tan K, Li J, Guan Z, Yang J, Shu J (2015) The identification of dynamic recrystallization and constitutive modeling during hot deformation of Ti55511 titanium alloy. Materials \& Design 84:204211, DOI 10.1016/j.matdes.2015.06.093, URL http://linkinghub.elsevier.com/retrieve/ pii/S0264127515004438

Zhao HK, Chan T, Merriman B, Osher S (1996) A Variational Level Set Approach to Multiphase Motion. Journal of Computational Physics 127(1):179-195, DOI 10.1006/jcph.1996.0167, URL http://www. sciencedirect.com/science/article/pii/S0021999196901679

Zhao P, Song En Low T, Wang Y, Niezgoda SR (2016) An integrated full-field model of concurrent plastic deformation and microstructure evolution: Application to 3D simulation of dynamic recrystallization in polycrystalline copper. International Journal of Plasticity 80:38-55, DOI 10.1016/j.ijplas.2015.12.010, URL http://dx.doi.org/10.1016/j.ijplas.2015.12.010,1509.04953

Zhu R, Liu Q, Li J, Xiang S, Chen Y, Zhang X (2015) Dynamic restoration mechanism and physically based constitutive model of $2050 \mathrm{Al}$ e Li alloy during hot compression. Journal of Alloys and Compounds 650:75-85, DOI 10.1016/j.jallcom.2015.07.182, URL http://dx.doi.org/10.1016/j.jallcom. 2015.07.182

Zouari M, Bozzolo N,Loge RE(2016)Mean field modelling of dynamic and post-dynamic recrystallization during hot deformation of Inconel 718 in the absence of $\delta$ phase particles. Materials Science and Engineering: A 655:1-17, DOI 10.1016/j.msea.2015.12.102, URL http://linkinghub.elsevier.com/ retrieve/pii/S0921509315307930

Zurob H, Brechet Y, Dunlop J (2006) Quantitative criterion for recrystallization nucleation in singlephase alloys: Prediction of critical strains and incubation times. Acta Materialia 54(15):3983-3990, DOI 10.1016/j.actamat.2006.04.028, URL http://linkinghub.elsevier.com/retrieve/pii/ S1359645406003181 